\title{
Radiographic Stents and Surgical Stents in Implant Placements: An Overview
}

IJCRR

Section: Healthcare

Sci. Journal Impact

Factor: 5.385 (2017)

ICV: 71.54 (2015)

\section{Prerna N. Kulkarni ${ }^{1}$, Nilesh S. Bulbule ${ }^{2}$, Dilip M. Kakade ${ }^{3}$, Neha V. Hakepatil ${ }^{1}$}

'MDS Student, Department of Prosthodontics and Crown \& Bridge, Dr. D.Y. Patil Vidyapeeth, Pimpri, Pune, Maharashtra, India; ${ }^{2} \mathrm{MDS}$, Professor, Department of Prosthodontics and Crown \& Bridge, Dr. D. Y. Patil Vidyapeeth, Pimpri, Pune, Maharashtra, India;

${ }^{3} \mathrm{MDS}, \mathrm{HOD}$ and Professor, Department of Prosthodontics and Crown \& Bridge, Dr. D. Y Patil Vidyapeeth, Pimpri, Pune, Maharashtra, India.

\section{ABSTRACT}

Aim: This article presents an overview about various simple techniques for fabrication of radiographic and surgical stents for implant placement.

Background: Dental implantology is now a feasible option to conventional prosthodontics. A need for predictable prosthesis has resulted in the emergence of prosthetically guided implantology. A radiographic stent is used for evaluation and determination of the accurate position for implant placement during the planning and for identification of the accurate site for the placement of implants during the surgical procedure. Radiographic and surgical stents help in placement of the implants in a precise and predetermined position and angulation, along with minimizing unnecessary osteotomy, results in an accurate design of prosthesis, reducing the time for implant placement and trauma caused to the patients thus increasing their comfort.

Conclusion: Using stents for implant placement helps achieve accurate position and angulation of implant.

Key Words: Diagnostic stent, Radiographic stents, Surgical Stents, Dental Implants

\section{INTRODUCTION}

Implants have now become an important option for replacement of missing teeth. Initially, the residual bone available and its quality determined the implant position and angulation. ${ }^{[1]}$

Prosthetically guided implantology was eventually developed due to the need for a predictable prosthesis. According to this concept, an accurate position of the implant is established at the diagnostic phase as per the pre-planned final restoration. ${ }^{[1]}$

During implant placement surgery, the position and angulation of the implant should be determined in an optimal position, considering the bone contour, the future prosthesis presence of any vital structures in the vicinity of the proposed implant site. One method to achieve an accurate implant position is to use a radiographic stent during the planning of implant treatment and use of surgical stents during surgery. $[2-3]$
The use of radiographic template with CBCT for planning implant position and a surgical stent during the surgery can play an important role. ${ }^{[1]}$

Use of surgical stent during surgery can help toprevent implant placement undesirable site, reduce unrequired osteotomy, result in appropriate prosthesis design, reduce the required surgical time and trauma, and increase patient comfort. ${ }^{[1]}$

An inadequate implants position and angulation may make prosthesis fabrication more complex, and worsen the prognosis of the implant by increasing the risk of surgical and prosthetic problems. It may lead to failure of the implant and will result in additional trauma to the patients, additional time and cost will be required of correction.

\section{Literature Review}

Naina Talwar et al(2010) in their paper have described a simple method for fabrication of a diagnostic stent using acrylic

Corresponding Author:

Dr. Prerna N. Kulkarni, Dr. D.Y. Patil Dental College and Hospital, Pimpri, Pune, Maharashtra, India-411018.

Contact Number: +91 8554808368; Email: kulprerna93@gmail.com.

ISSN: 2231-2196 (Print)

Received: 06.03.2019
ISSN: $0975-5241$ (Online)

Revised: 07.04 .2019
Accepted: 22.05 .2019 
and gutta-percha as a radiopaque material for radiographic evaluation. After the radiographic evaluation it can be modified to be used as surgical stent during the implant placement. They have suggested a method for fabrication of a simple and cost effective stent for implant placement and its advantages over the other techniques of stent fabrication. ${ }^{[1]}$

Yen-Chen Ku and Yu-Fu Shen (2000) have described a method for fabrication of a radiographic and surgical stent. A vacuum-formed matrix that is usually used in the fabrication of fixed provisional prostheses was used in the fabrication of stents for radiographic examination and in the surgical stage of implant therapy. A simple method of fabricating a vacuum-formed matrix filled with clear acrylic resin and a gutta-percha marker was described. ${ }^{[4]}$

Ingeborg J. De Kok et al (2014) have described various methods for fabricating radiographic stents for implant placement. The different methods described are - using an existing prosthesis with radiopaque markers, using a thermoplastic shim incorporating radiopaque markers, using radiopaque teeth in a mucosa or tooth supported stent and fabricating a radiopaque resin duplicate of a diagnostic wax-up. ${ }^{[5]}$

\section{Techniques}

\section{Radiographic stent}

Various techniques can be used for the fabrication of radiographic stents.

They are -

\section{Using an existing prosthesis with radiopaque markers} (Fig. 1) ${ }^{[5]}$

a. Existing prosthesis (Removable partial denture) of patient used as a radiographic stent.

b. A thin layer of sticky wax applied to the mid-facial region of tooth.

c. A lead foil is stuck to the sticky wax.

d. Radiograph of the patient with the stent in place.

2. Using a thermoplastic shim incorporating radiopaque markers (Fig. 2) ${ }^{[5]}$

a. Plaster cast of patient showing anterior teeth missing.

b. Wax-up done and cast duplicated.

c. Thermoplastic shim fabricated and radio-opaque material applied to the shim.

d. Radiograph of the patient with the shim in place.

3. Using radio-opaque teeth in mucosa or tooth-supported stent (Fig. 3) ${ }^{[5]}$

i. Plaster cast of the patient with missing teeth.

ii. Wax-up done on the cast.

iii. Cast duplicated and thermoplastic shim fabricated.

iv. Radio-opaque acrylic teeth placed in the shim.

v. Radiograph of the patient with the shim in place.

4. Radiopaque resin duplicate of the prosthesis or a diagnostic wax-up (Fig 4) ${ }^{[5]}$
1. Maxillary denture of the patient duplicated in a radiopaque resin.

2. Stereolithographic surgical stent fabricated from derived treatment plan

\section{USING THE GENERATED SCAN DATA (Fig.. 5) [5] $^{[5}$}

a. 3-D reconstruction of the edentulous mandible with superimposed prosthesis with the planned tooth position in place.

b. Determined position of the implant based on data acquired.

c. Design of the surgical stent virtually designed.

d. Surgical stent fabricated using stereolithography.

\section{Surgical Stent (Fig. 6) ${ }^{[1]}$}

1. Maxillary and Mandibular impressions are made using irreversible hydrocolloid impression material and poured in gypsum.

2. The casts are articulated on an articulator. Wax up is done on the mounted cast.

3. This cast is then duplicated in gypsum.

4. Occlusal two third of the prosthesis is trimmed on the duplicated cast. The location of access holes both mesio-distally and bucco-lingually is determined.

5. A stent was fabricated as a plate using autopolymerizing acrylic resin on the trimmed teeth and the position of the implant is transferred on the plate.

6. A channel is made in the center of the stent through the predetermined mesio-distal and bucco-lingual center. The channel is filled with gutta percha used as the radiopaque marker.

7. A Cone-Beam Computed Tomography scan of the implant site with the stent in the patient's mouth is obtained.

8. The Cone-Beam Computed Tomography scan images are analyzed and tracings of images are done for determining three dimensional position of the implant.

\section{DISCUSSION}

For a successful implant treatment, it is important to place the implant at an accurate pre-determined position. The mesio-distal position of the implant should be such that, it helps in papilla preservation and provides an esthetic restoration profile. ${ }^{[6]}$

Implants have to be placed a minimum of $1.5 \mathrm{~mm}$ from the adjacent tooth and $3 \mathrm{~mm}$ from an adjacent implant. ${ }^{[7,8,9]}$

When more than one implant has to be placed, they should be placed parallel to each other or it might lead to non-axial loading that might result in failure of implants. ${ }^{[10]}$

To achieve these objectives, the use of radiographic and surgical stent has been advocated. According to the literature, implants that have been positioned using stents are more 
accurately positioned as compared to those placed without stents. ${ }^{[11,12]}$

A surgical guide allows the placement of the implant along planned prosthetic axes during surgery. A radiographic stent allows visualizing the planned implant axis, position of the definitive prosthesis, emergence site, available space for the attachment components, and thickness of the mucosa overlying the bone. The radiographic stent can be transformed into a surgical stent after the treatment planning has been completed. During surgery, this removable surgical stent offers ease in implant placement without compromising access to the implant sites. ${ }^{[13]}$

\section{CONCLUSION}

Dental implantology has come up as a feasible option to conventional prosthodontics. Using stents for implant placement helps in achieving precise position of implants. Even an inexperienced surgeon can achieve better results by using radiographic and surgical stents during implant placement.

\section{Source of Funding: Nil}

\section{Conflict of Interest: Nil}

\section{ACKNOWLEDGEMENTS}

We place on record, our sincere gratitude to the HOD and professors, Department of Prosthodontics and Crown \& Bridge, for their constant help and encouragement. We also thank them for their expert, sincere and valuable guidance extended to us.

We would like to extend our gratitude to Dr. Paresh Kale, Dr. Vedashree Natu, Dr. Tejas Agarwal and Dr. Vaibhav Jathar for their contribution to this paper.

We acknowledge the immense help received from the scholars whose articles are cited and included in references of this manuscript. We are also grateful to authors / editors / publishers of all those articles, journals and books from where

the literature for this article has been reviewed and discussed.

We would also like to extend my sense of gratitude to one and all who, directly or indirectly, have lent their helping hand in this venture.

\section{REFERENCES}

1. Naina Talwar, Balendra Pratap Singh, Pooran Chand, U. S. Pal. Use of Diagnostic and Surgical Stent: A Simplified Approach for Implant Placement; J Indian Prosthodont Soc (Oct-Dec 2010) 10(4):234-239.

2. Jun Kuo, Chih-Cheng Hung. An assistant guide for accurate placement of dental implants; Becker CM, Kaiser DA. Surgical guide for dental implant placement. J Prosthet Dent 2000; 83:248-51.

3. Yen-Chen $\mathrm{Ku}$ and $\mathrm{Yu}-\mathrm{Fu}$ Shen. Fabrication of a radiographic and surgical stent for implants with a vacuum former. J Prosthet Dent 2000;83:252-3.

4. Ingeborg J. De Kok, Ghadeer Thalji, Matthew Bryington, Lyndon F. Cooper. Radiographic Stents Integrating Treatment Planning and Implant Placement. Dent Clin N Am 58 (2014) 181-192.

5. Lazzara RJ (1993) Effect of implant position on implant restoration design. J Esthet Dent 5:265-269.

6. Almong DM, Torrado E, Meitner SW (2001) Fabrication of imaging and surgical guides for dental implants. J Prosthet Dent 85:504-508.

7. Horiuchi M, Ichikawa T, Kanitani H et al (1995) Pilot-hole preparation for proper implant positioning and the enhancement of bone formation. J Oral Implantol 21:318-324.

8. Almog DM, Onufrak JM, Hebel K et al (1995) Comparison between planned prosthetic trajectory and residual bone trajectory using surgical guides and tomography - a pilot study. J Oral Implantol 21:275-280.

9. Taylor TD, Agar JR, Voigiatzi (2000) Implant prosthodontics: current perspective and future directions. Int J Maxillofac Implants 15:66-75.

10. Engelman MJ, Sorenson JA, Moy P (1988) Optimum Placement of Osseointegrated implants. J Prosthet Dent 59:467-473.

11. Modica F, Fava C, Benech A et al (1991) Radiologic-prosthetic planning of the surgical phase of the treatment of edentulism by osseointegrated implants: an in vitro study. J Prosthet Dent 65:541-546.

12. Claudine Wulfman, DDS, MS, A Alain Hadida, MD, MS, PhD, b and Christophe Rignon-Bret. Radiographic and surgical guide fabrication for implant-retained mandibular overdenture (J Prosthet Dent 2010;103:53-57).

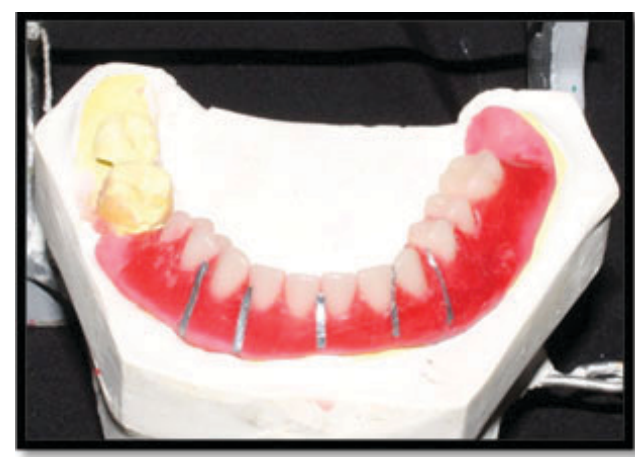

Figure 1a: Lead Foil placed on patients RPD.

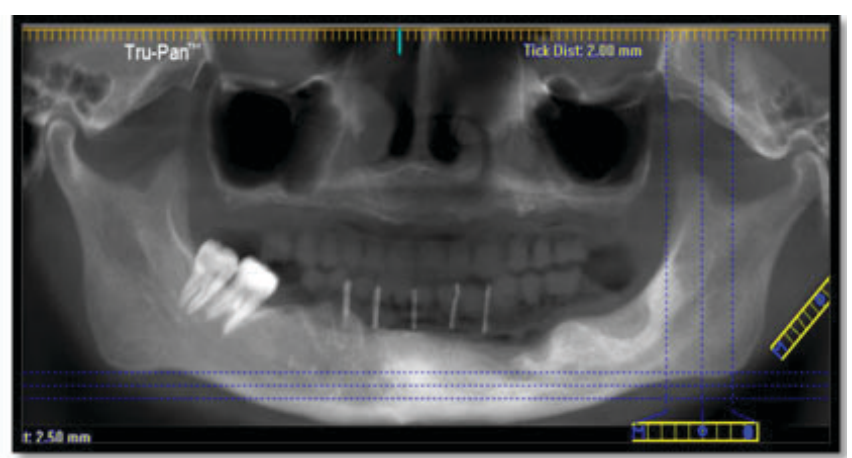

Figure $1 \mathrm{~b}$ : Radiograph of the patient with the stent in place. 


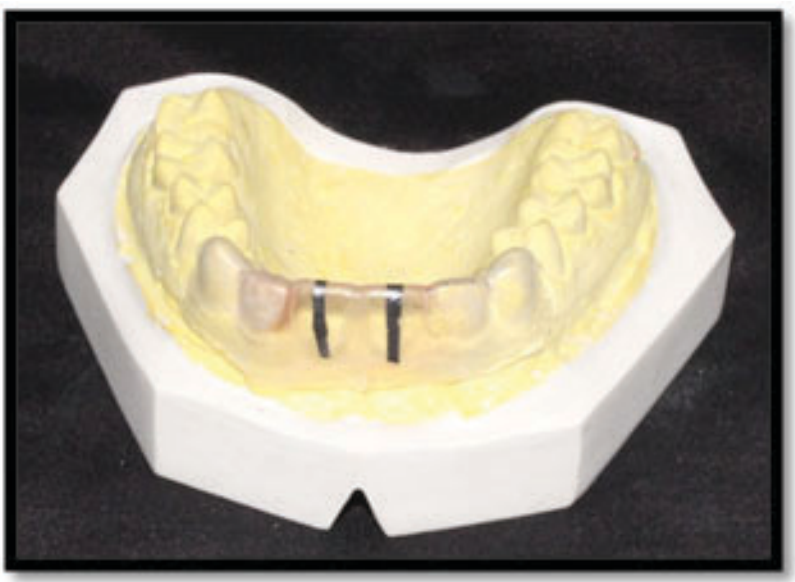

Figure 2a:Thermoplastic shim with radiopaque markers.

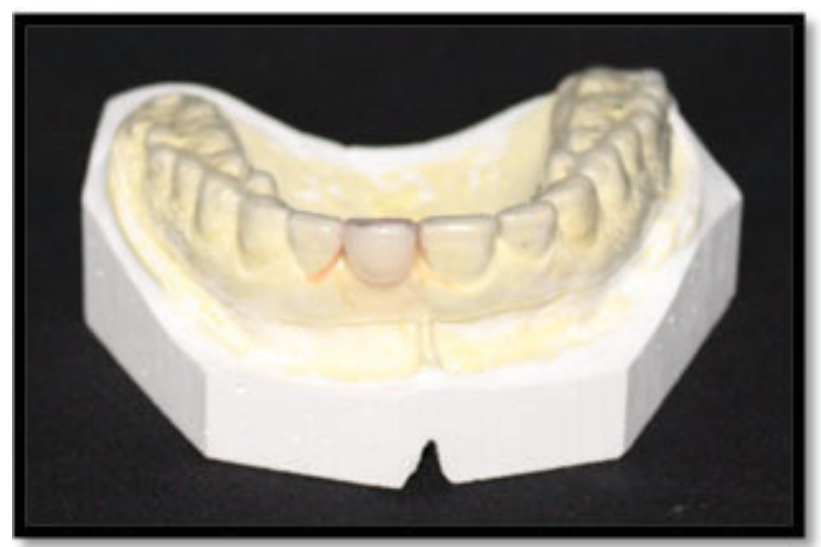

Figure 3a: Radio-opaque acrylic teeth placed in the shim.

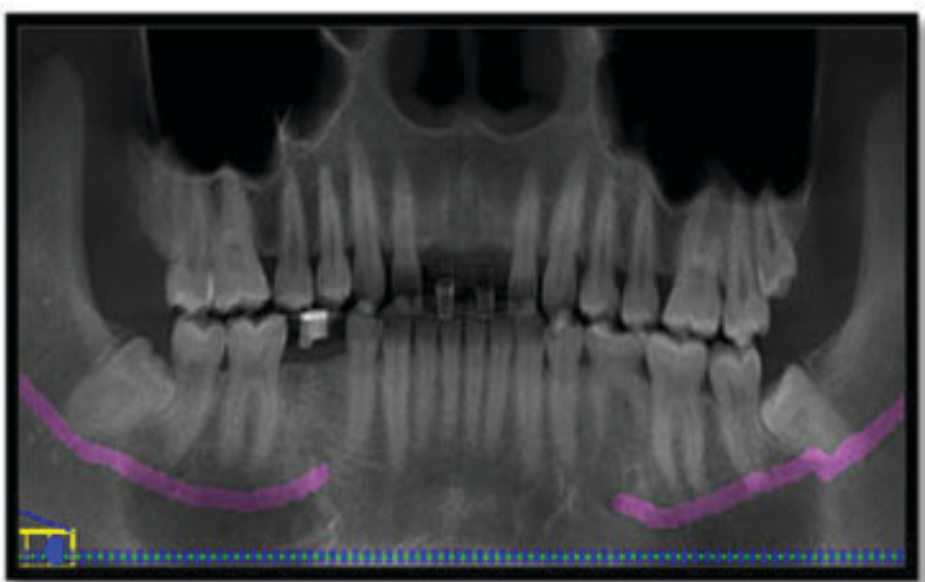

Figure $2 b$ : Radiograph of the patient with shim in place.

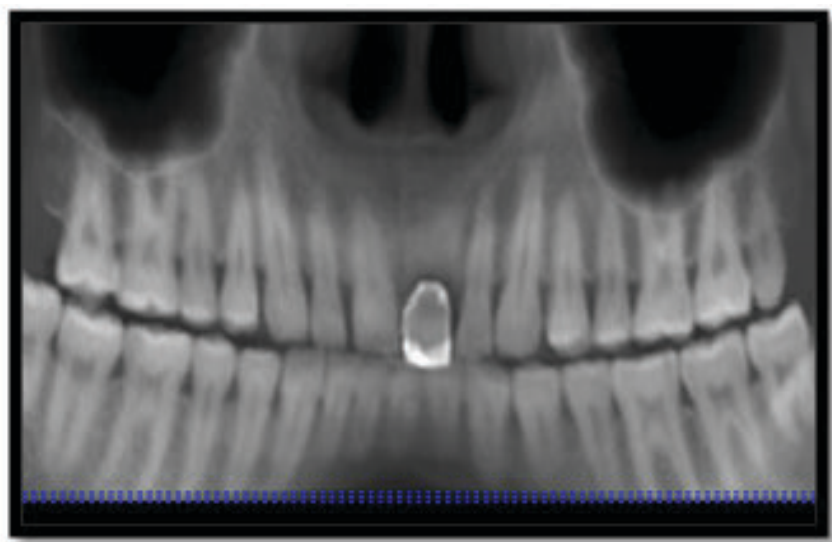

Figure 3b: Radiograph of the patient with the shim in place.

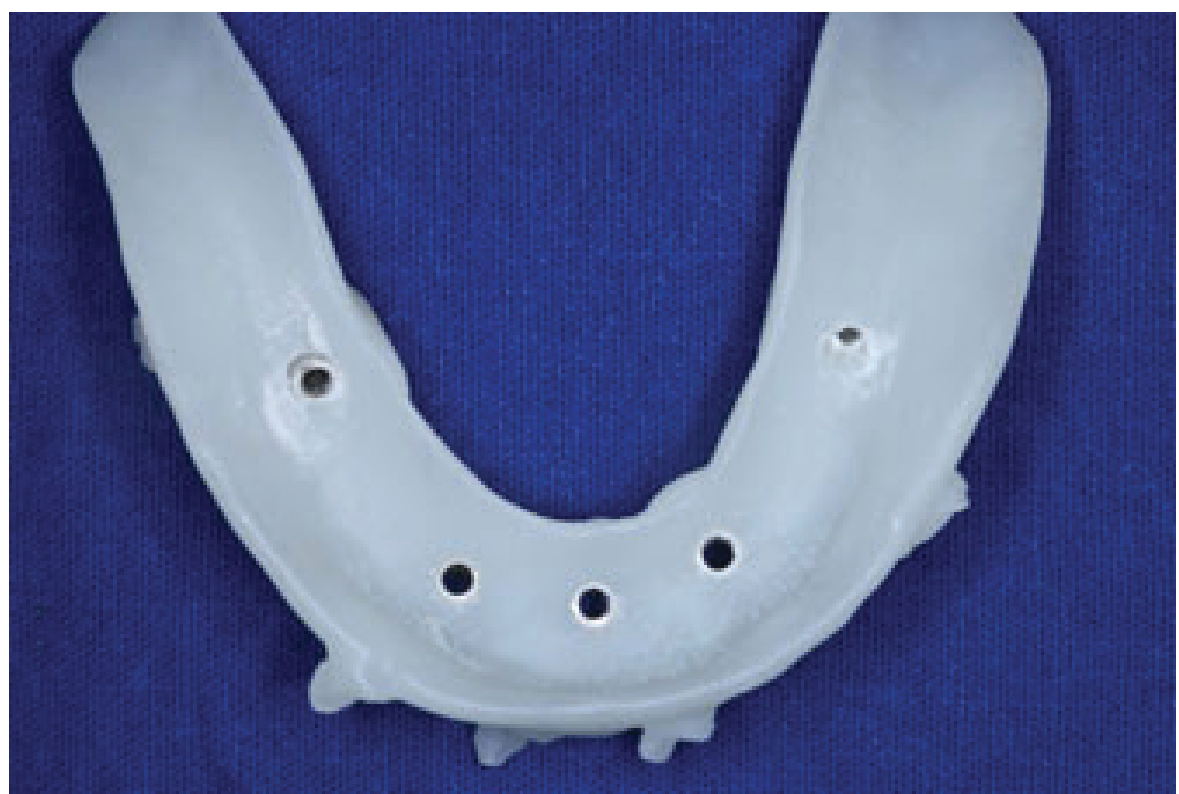

Figure 4: Stereolithographically fabricated surgical guide. 


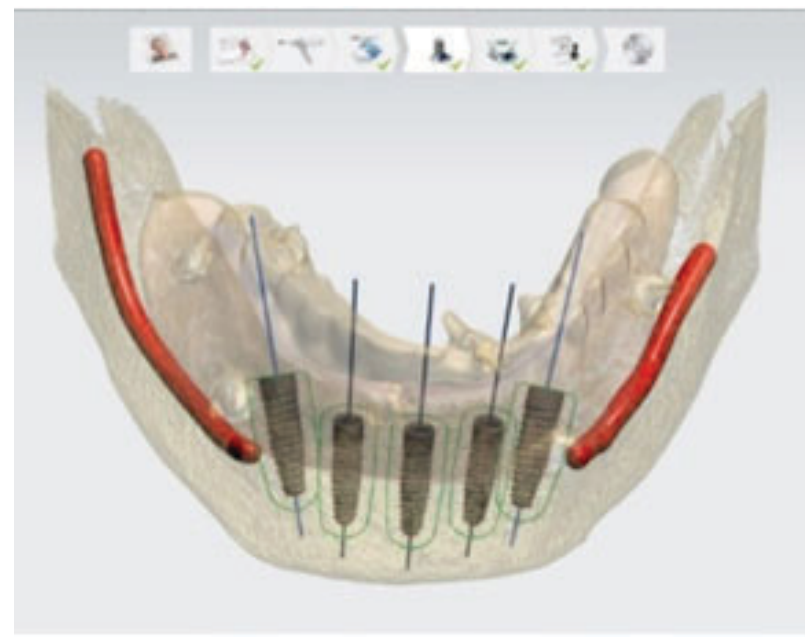

Figure 5a: Virtually designed surgical stent.

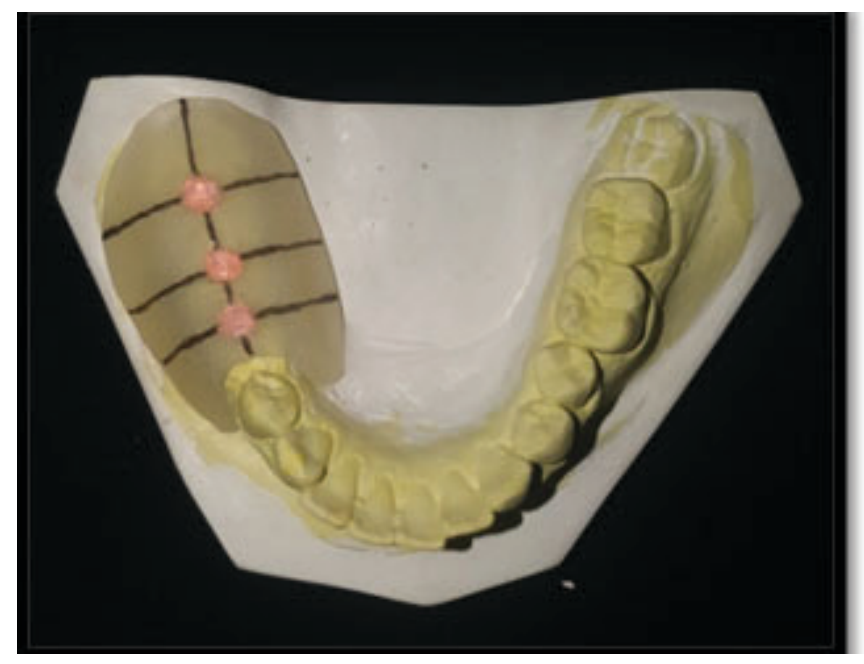

Figure 6a: Radiographic stent fabricated with auto-polymerizing resin and gutta-percha.

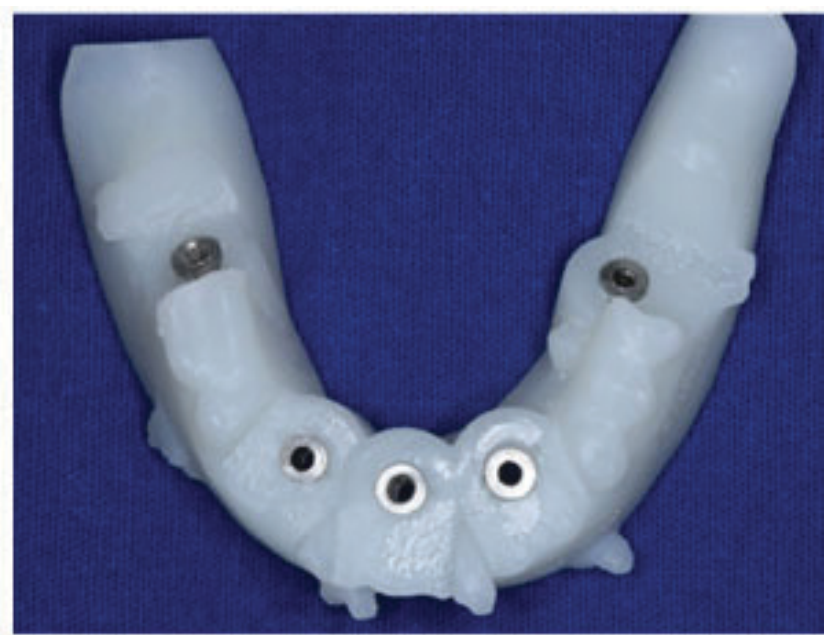

Figure 5b: Surgical stent fabricated using stereolithogarphy.

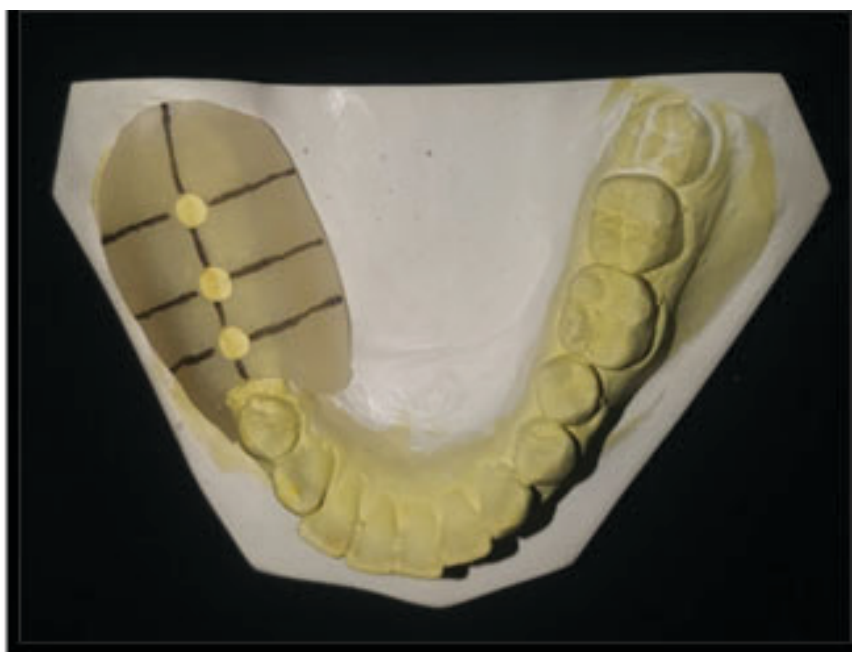

Figure 6b: Radiographic stent converted into a surgical stent to be used during implant placement. 